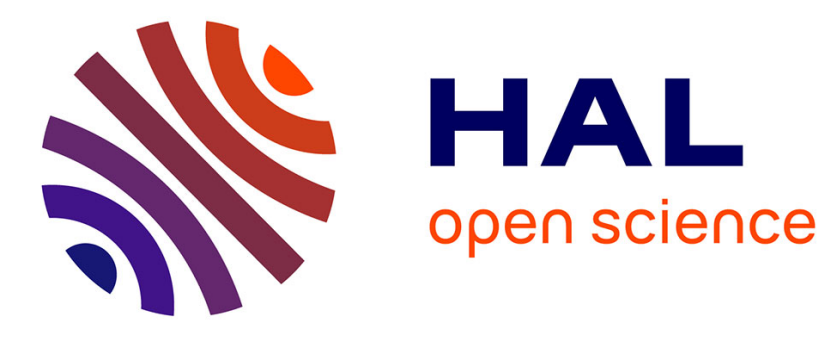

\title{
Effect of RGPP process on properties of Cr-Si-N coatings
}

\author{
Amel Zairi, Corinne Nouveau, Ahmed Beb Cheikh Larbi, Alain Iost, Nicolas \\ Martin, Aurélien Besnard
}

\section{- To cite this version:}

Amel Zairi, Corinne Nouveau, Ahmed Beb Cheikh Larbi, Alain Iost, Nicolas Martin, et al.. Effect of RGPP process on properties of Cr-Si-N coatings. Surface Engineering, 2014, 30 (8), pp.606-611. 10.1179/1743294414Y.0000000280 . hal-01060107

\section{HAL Id: hal-01060107 https://hal.science/hal-01060107}

Submitted on 2 Sep 2014

HAL is a multi-disciplinary open access archive for the deposit and dissemination of scientific research documents, whether they are published or not. The documents may come from teaching and research institutions in France or abroad, or from public or private research centers.
L'archive ouverte pluridisciplinaire HAL, est destinée au dépôt et à la diffusion de documents scientifiques de niveau recherche, publiés ou non, émanant des établissements d'enseignement et de recherche français ou étrangers, des laboratoires publics ou privés. 


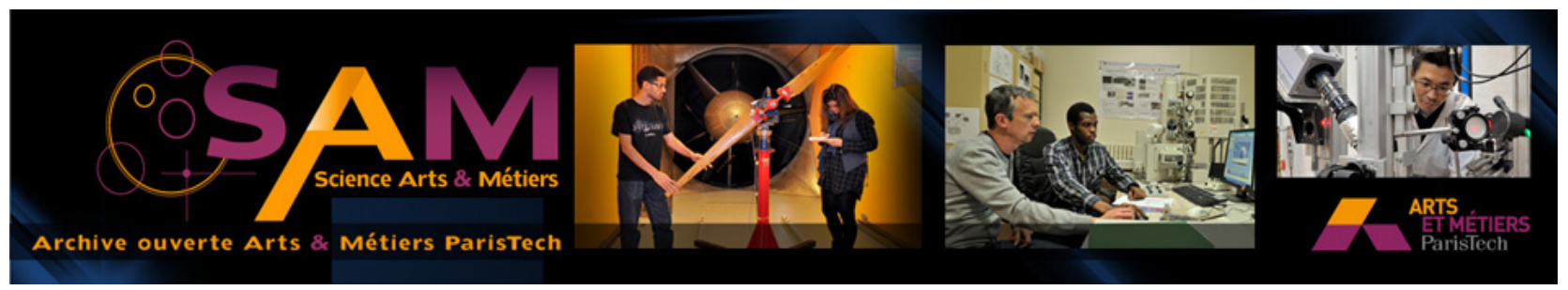

Science Arts \& Métiers (SAM)

is an open access repository that collects the work of Arts et Métiers ParisTech researchers and makes it freely available over the web where possible.

This is an author-deposited version published in: http://sam.ensam.eu

Handle ID: .http://hdl.handle.net/10985/8357

\section{To cite this version :}

Amel ZAIRI, Corinne NOUVEAU, Ahmed Beb Cheikh LARBI, Alain IOST, Nicolas MARTIN, Aurélien BESNARD - Effect of RGPP process on properties of $\mathrm{Cr}-\mathrm{Si}-\mathrm{N}$ coatings - Surface Engineering - Vol. 30, n8, p.606-611- 2014 


\title{
Effect of RGPP process on properties of $\mathrm{Cr}-\mathrm{Si}-\mathrm{N}$ coatings
}

\begin{abstract}
A. Zairi*1,2 , C. Nouveau ${ }^{1}$, A. B. C. Larbi ${ }^{2}$, A. lost $^{3}$, N. Martin ${ }^{4}$ and A. Besnard ${ }^{1}$
CrSiN films were deposited by reactive radio frequency magnetron sputtering in an $\mathrm{Ar}+\mathrm{N}_{2}$ gas mixture. The nitrogen gas was injected in the deposition chamber using two methods: the classical constant injection and pulsed injection, the latter known as the reactive gas pulsing process (RGPP). Argon gas was continuously injected, whereas nitrogen gas was pulsed during the deposition. The RGPP was used to adjust the chemical composition and, consequently, allowed the improvement of the coating characteristics. The effect of process parameters such as silicon content and gas pulsing conditions (especially duty cycle $\alpha$ ) on the crystallographic structure, chemical composition and morphology of the CrSiN layers is reported. It was found that the surface morphology evolves from a pyramid-like feature for $100 \%$ duty cycle to a typical cauliflower-like aspect, when duty cycle decreases to $84 \%$. For shorter duty cycles, the growth produced a denser coating, with round and finer clusters.
\end{abstract}

Keywords: Thin films, CrSiN, Nitrogen pulsed injection, rf magnetron sputtering

\section{Introduction}

Coating of mechanical components is one of the preferred solutions adopted in demanding industries, such as cutting tools, automotive, aeronautic and naval, aiming to improve the service life of the different devices. In general, the solutions are based on a choice between the desired properties of the coating and their optimal deposition conditions.

The current range of available coating compositions includes those based on titanium, chromium, aluminum or tungsten combined with various reactive gases, giving rise to the binary compounds TiN, CrN or $\mathrm{WC}^{1-3}$ the ternary compounds TiAlN (Ref. 4) or CrAlN and, even, quaternary compounds such as TiAlCN or AlCrCN. Each composition corresponds to a specific performance level and, of course, will have both advantages and limitations. Among these coatings, $\mathrm{CrN}$ is a very interesting coating due to its combination of high mechanical and thermal properties with good corrosion resistance. ${ }^{5,6}$ Besides, it could be deposited at low temperature, which makes it appropriate for coating deposition of temperature sensitive materials and low melting point metals. ${ }^{7}$ It is well known that the microstructural characteristics of these coatings are highly dependent on the sputtering conditions, which affect the coating thickness and may introduce

\footnotetext{
${ }^{1}$ Arts et Metiers ParisTech - LaBoMaP, Rue Porte de Paris, Cluny F71250, France

${ }^{2}$ Ecole Nationale Supérieure des Ingénieurs de Tunis - LMMP, Université de Tunis, 5 Avenue Taha Hussein, Montfleury 1008, Tunisia ${ }^{3}$ Arts et Metiers ParisTech - MSMP, 8 Boulevard Louis XIV, Lille F-59046, France

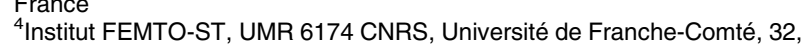
Avenue de l'observatoire, Besançon Cedex F-25044, France

*Corresponding author, email amal.zairi@gmail.com
}

microstrains in the coatings. ${ }^{8}$ It was shown that the additions of $\mathrm{Si}$ to a $\mathrm{CrN}$ binary coating, to form $\mathrm{CrSiN}$, have brought about a considerable improvement in the coating quality. In this case, a better distribution of the nanoscopic structure takes place with the formation of a solid solution, which strengthens due to the substitution of $\mathrm{Cr}$ by $\mathrm{Si}^{9}{ }^{9-12}$

These results were obtained mainly for $\mathrm{CrSiN}$ coatings deposited by reactive magnetron sputtering techniques. It is now recognised that this process has an undesirable hysteresis loop commonly observed as the gas flow is varied during conventional sputtering, which produces an unstable process, therefore causing a lack of uniformity with regard to the initially desired composition and density of the coating. Additionally, poisoning of the cathode takes place that acts negatively on the sputtering rate of the metallic target. In order to address these problems, several solutions have been proposed. ${ }^{5,13,14}$ Among these, the use of high pumping speeds or shutters is commonly developed to reduce the instability phenomena by eliminating the hysteresis loops of the deposition parameters. According to the geometry of the sputtering chambers and the pumping systems, the above solutions were found to be limited. For this reason, other solutions were proposed and were based either on the feedback controls of the reactive gas supply or on the low frequency pulsing potentials applied to the target. ${ }^{15-17}$ Some investigations were interested on sputtering of metallic nitride and oxide coatings using an original method with reactive sputter deposition in which nitrogen gas pulsed on and off at regular times. ${ }^{18-20}$ It has to be mentioned that a periodic introduction of the reactive gas has been developed for single systems with one target $(\mathrm{M})$ and one reactive gas $\left(\mathrm{O}_{2}\right.$ or $\left.\mathrm{N}_{2}\right){ }^{21,22}$ Few works have been devoted to the 


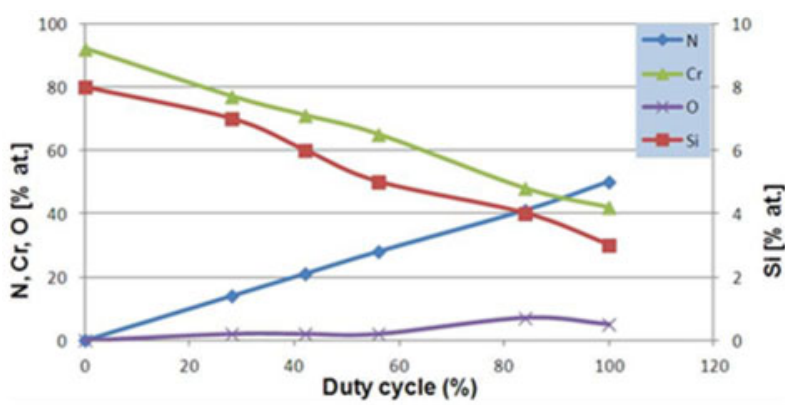

1 Rectangular pulsing of nitrogen mass flowrate versus time: pulsing period $T$, minimum and maximum flowrates $q_{\mathrm{N} 2 \mathrm{~m}}$ and $q_{\mathrm{N} 2 \mathrm{M}}$ and $t_{\mathrm{ON}}$ and $t_{\mathrm{OFF}}$ times are defined

processing behaviour ${ }^{23,24}$ of the complex system $\mathrm{M}+\mathrm{O}_{2}+\mathrm{N}_{2}$.

The reactive gas pulsing process (RGPP) has the advantage of coping with instability phenomena and offers a wide range of uniform compositions. ${ }^{25}$ Reactive gas pulsing process is based on magnetron sputtering in which the flow of the reactive gas is periodically introduced according to rectangular, exponential or sine signals. The rectangular and exponential signals have been determined to be the most appropriate. ${ }^{26}$

The present work is carried out in order to determine the influence of the variation of the injection time of the reactive gas (i.e. duty cycle) on the composition, especially on the $\mathrm{Si}$ content, as well as on the surface morphology and structure of the coatings.

\section{Experimental}

The chromium silicon nitride coatings were deposited on $\mathrm{Si}$ (100) substrates by means of radio frequency (rf) dual magnetron sputtering in a commercial Nordiko 3500 vacuum reactor. These substrates have an area of $10 \times 10 \mathrm{~mm}$ and a thickness of $\sim 380 \mu \mathrm{m}$. Two targets of high purity $(99.95$ at- $\% \mathrm{Cr}$ and 99.99 at- $\% \mathrm{Si})$, with $101.6 \mathrm{~mm}$ in diameter and $3 \mathrm{~mm}$ in thickness were $\mathrm{rf}$ sputtered at $13.56 \mathrm{MHz}$. Before deposition, the samples were ultrasonically cleaned with acetone for $10 \mathrm{~min}$ and with ethanol of $95^{\circ}$ for $5 \mathrm{~min}$. Subsequently, they were rinsed in deionised water, dried and stored in desiccators before deposition. Substrates were in situ etched by means of ion bombardment in pure argon at $1 \mathrm{~Pa}$ with an applied bias voltage of $1 \mathrm{kV}$ for $10 \mathrm{~min}$ in order to remove surface oxides and pollution. Substrates were located at a distance of $80 \mathrm{~mm}$ from the targets. No heating was applied during the deposition. The $\mathrm{Cr}$ and Si targets were presputtered in a pure argon atmosphere at $0.4 \mathrm{~Pa}$ for $5 \mathrm{~min}$ in order to clean their surface. The sputtering power applied onto the $\mathrm{Si}$ and $\mathrm{Cr}$ targets was of 125 and $550 \mathrm{~W}$ respectively, which corresponded to target voltages of -400 and $-900 \mathrm{~V}$ respectively. The deposition time was adjusted so as to obtain a thickness close to $2 \mu \mathrm{m}$. The nitrogen mass flowrate was periodically pulsed versus time using a rectangular signal (Fig. 1).

The pulsing period $T$ and maximum and minimum nitrogen flowrates $q_{\mathrm{N} 2 \mathrm{M}}$ and $q_{\mathrm{N} 2 \mathrm{~m}}$ were kept constant at $T=10 \mathrm{~s}, q_{\mathrm{N} 2 \mathrm{M}}=4 \mathrm{sccm}$ and $q_{\mathrm{N} 2 \mathrm{~m}}=0 \mathrm{sccm}$, whereas the $t_{\mathrm{ON}}$ and $t_{\mathrm{OFF}}$ times were systematically changed. This corresponds to a duty cycle $\alpha=t_{\mathrm{ON}} / T$, which varies from 0 to $100 \%$ of $T$. These pulsing conditions were chosen in

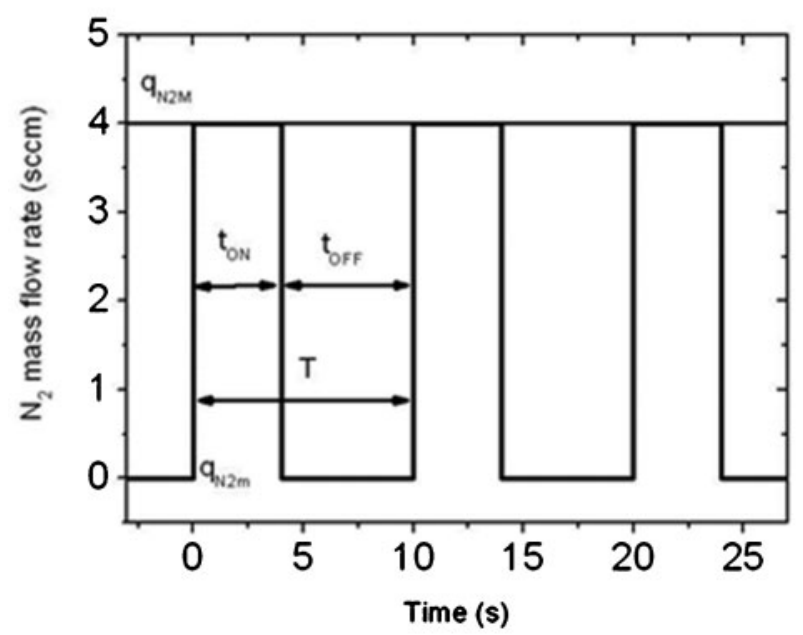

2 Variation of chemical composition of coatings with duty cycle $\alpha$

order to easily alternate the reactive sputtering process between the metallic and compound sputtering modes. ${ }^{20,27,28}$ The crystallographic structure and preferential orientation of the coatings were characterised by means of a Philips X'Pert thin film X-ray diffractometer. The X-ray source was $\mathrm{Cu} K_{\alpha}$ radiation $(\lambda=1 \cdot 5418 \AA)$, which operated at $40 \mathrm{kV}$ and $30 \mathrm{~mA}$ in the $\theta / 2 \theta$ configuration. The morphology and chemical composition of the coatings were determined by means of high resolution scanning electron microscopy (JEOL JSM 7600-F HR-SEM) coupled with energy dispersive spectroscopy (EDS). The surface morphology and roughness of layers were analysed by atomic force microscopy (AFM Digital nanoscope IIIa multimodes) with taping mode.

\section{Results and discussion}

\section{Chemical composition with EDS microanalysis}

The chemical composition of the coatings has been analysed by means of EDS, and the results are presented in Fig. 2. The $\mathrm{Cr}$ and $\mathrm{Si}$ concentrations gradually decrease from 94 to 42 at- $\%$ and from 8 to 3 at $\%$ respectively, as a function of the duty cycle $\alpha$, whereas the $\mathrm{N}$ content increases and reaches 50 at $\%$ for $\alpha=100 \%$ (constant supply of the nitrogen gas).

The continuous evolution of the chemical composition is connected to the alternation of the reactive sputtering process between the nitriding and elemental sputtering modes. It could be seen that, by adjusting the duty cycle, both the poisoning and cleaning phenomena of the target surface can be favoured by the regulation of the $t_{\mathrm{ON}}$ and $t_{\mathrm{OFF}}$ times. As a result, for the longest $t_{\mathrm{ON}}$ times, more nitrogen can be incorporated in the film during a single pulsing period and less can be removed from the target surface during the $t_{\mathrm{OFF}}$ time. Note that the films have a few amount of oxygen in their composition $(<7$ at- $\%)$, as shown in Fig. 2.

Owing to the higher reactivity between nitrogen and silicon as compared with chromium, more nitrogen will be consumed by the silicon target and the potential bias of targets will decrease. This reduction is confirmed by the decline of the applied power from 550 to $490 \mathrm{~W}$, which can explain the value of the silicon concentration in the coatings. 


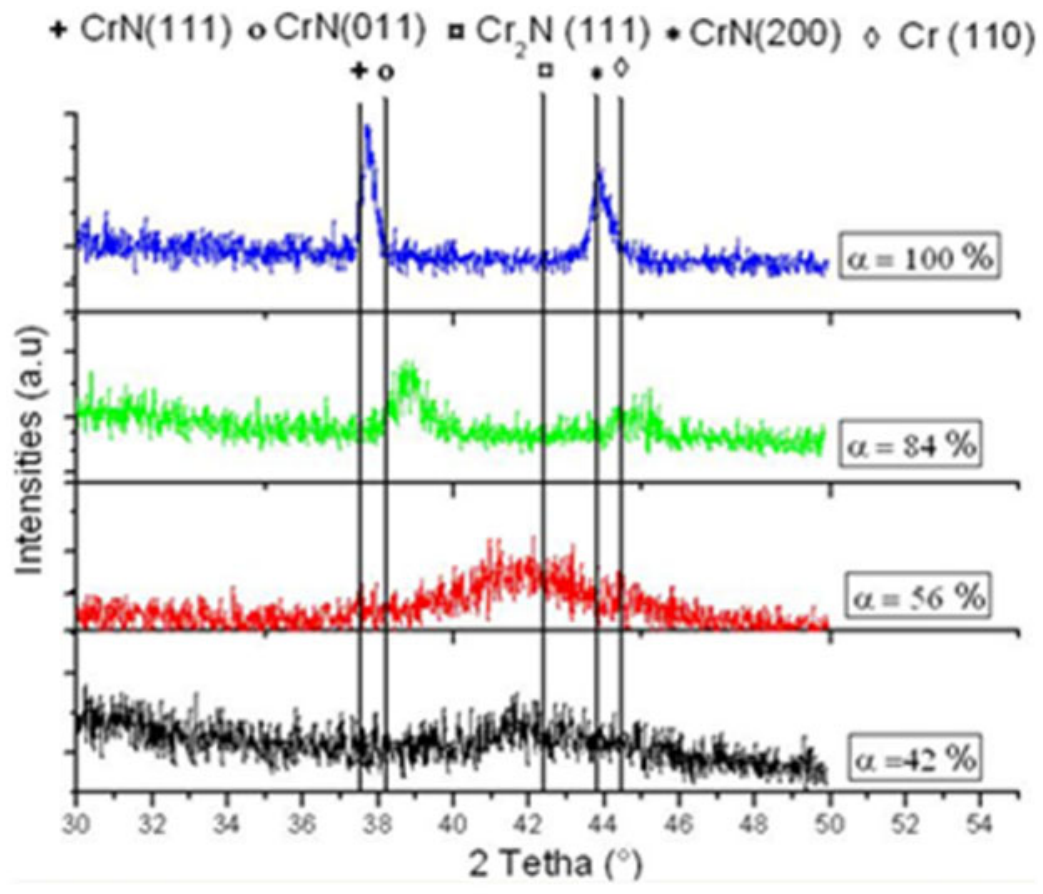

3 X-ray diffraction patterns of CrSiN coatings deposited on Si (100) substrates with various duty cycles

\section{Structure of RGPP $\mathrm{Cr}-\mathrm{Si}-\mathbf{N}$ coatings}

X-ray diffraction (XRD) patterns of $\mathrm{CrSiN}$ films deposited onto the Si substrates, obtained with different values of $\alpha$, of $0,42,56,84$ and $100 \%$, are shown in Fig. 3. All these coatings were deposited with the same nitrogen flow $(4 \mathrm{sccm})$ injected with a rectangular signal, as shown in Fig. 1.

When $\alpha$ reaches $42 \%$, the $\mathrm{N} / \mathrm{Cr}$ ratio is $\sim 0 \cdot 3$, and the structure becomes a mixture of $\mathrm{Cr}$ and $\mathrm{Cr}_{2} \mathrm{~N}$ phases. In this case, a weak and broad diffracted peak is recorded, which may be due to the formation of a poorly crystallised $\mathrm{Cr}_{2} \mathrm{~N}$ phase.

This observation is confirmed for $\alpha=56 \%$, where $\mathrm{N} / \mathrm{Cr}$ ratio reaches $0 \cdot 42$, which is close to $0 \cdot 5$. It is considered that the $\mathrm{Cr}_{2} \mathrm{~N}$ phase is present with the diffraction of (111) planes, according to the International Centre for Diffraction Data file no. 00-035-0803. A more intense and narrow peak is measured, but the film still remains poorly crystallised. For duty cycle of $84 \%$, diffractions of (111) and (200) planes are recorded at $2 \theta=37.6$ and $43.8^{\circ}$ respectively, due to the presence of the cubic $\mathrm{CrN}$ phase (International Centre for Diffraction Data no. 01077-0047). These peaks are larger, less intense and shifted to higher angles as a consequence of the deposition of nitrogen deficient $\mathrm{CrN}$ films with an $\mathrm{N} / \mathrm{Cr}$ ratio of 0.85 and a weakly crystallised structure.

When the ratio of $\mathrm{N} / \mathrm{Cr}$ is 1.2 at $\alpha=100 \%$, the film is overstoichiometric, and the structure is similar to that corresponding to $\alpha=84 \%$. Coatings are more crystallised, which means that grain growth has occurred, minimising the total energy. This observation is in agreement with the grain size of coatings, which increases with the duty cycle (Fig. 4).

No diffracted peaks from $\mathrm{Si}$ and/or $\mathrm{SiN}_{\mathrm{x}}$ phases were observed in this diffraction pattern, indicating that they are in an amorphous state. Therefore, as $\alpha$ increases up to $100 \%$, the obtained $\mathrm{CrSiN}$ coatings are expected to be composed of crystallised $\mathrm{CrN}_{\mathrm{x}}$ grains, within an amorphous $\mathrm{SiN}_{\mathrm{x}}$ matrix.
The increase in injection time leads also to an increase in nitrogen in the chamber along with the argon gas. When time injection is more important, the eneregetic bombardment is more significant, which induce more atomic mobility and thermal diffusion. ${ }^{29}$ This phenomenon leads to relaxation stress that may occur including the reduction in strain energy. It can be seen that samples with high injection time $t_{\mathrm{ON}}$ are more textured with a preferential orientation in $\mathrm{CrN}$ (111).

Top and cross-section views by HR-SEM images of the $\mathrm{CrSiN}$ films deposited on $\mathrm{Si}(100)$ substrates with different duty cycles are shown in Fig. 4. These results indicate that the structure is strongly affected by the pulsing process. Coatings deposited at $\alpha=100 \%$ show a very dense columnar structure, which becomes wider as the nitrogen injection time $t_{\mathrm{ON}}$ decreases. Despite the high resolution of the SEM used, no multilayered structure was observed in these cross-section micrographs, which leads to the conclusion that a homogeneous structure is obtained when the duty cycle is varied with a pulsing period of $10 \mathrm{~s}$.

Micrographs of the top surface are also shown in Fig. 4. It could be observed that a strong variation of surface morphologies takes place as a function of the $\alpha$ values. All the films exhibit a columnar structure typical of physical vapour deposition coatings, which has grown perpendicular to the substrate, as shown in Fig. 4, which corresponds to the coating deposited with a value of $\alpha=56 \%$. Their morphology is characteristic of zone $\mathrm{T}$ (growth of columns with cauliflower-like appearance, not very dense) of the Thornton's structure zone model, except the one which has been obtained at $\alpha=100 \%$.

This result confirms the XRD patterns that showed amorphous or weakly crystallised coatings, which can be explained by the effect of the silicon content.

The layer obtained at $\alpha=100 \%$ presents a growth according to zone 2 (growth of wider columns with pyramidal top shapes). This confirms the presence of (111) and (200) crystallographic planes of the fcc $\mathrm{CrN}$ phase. 

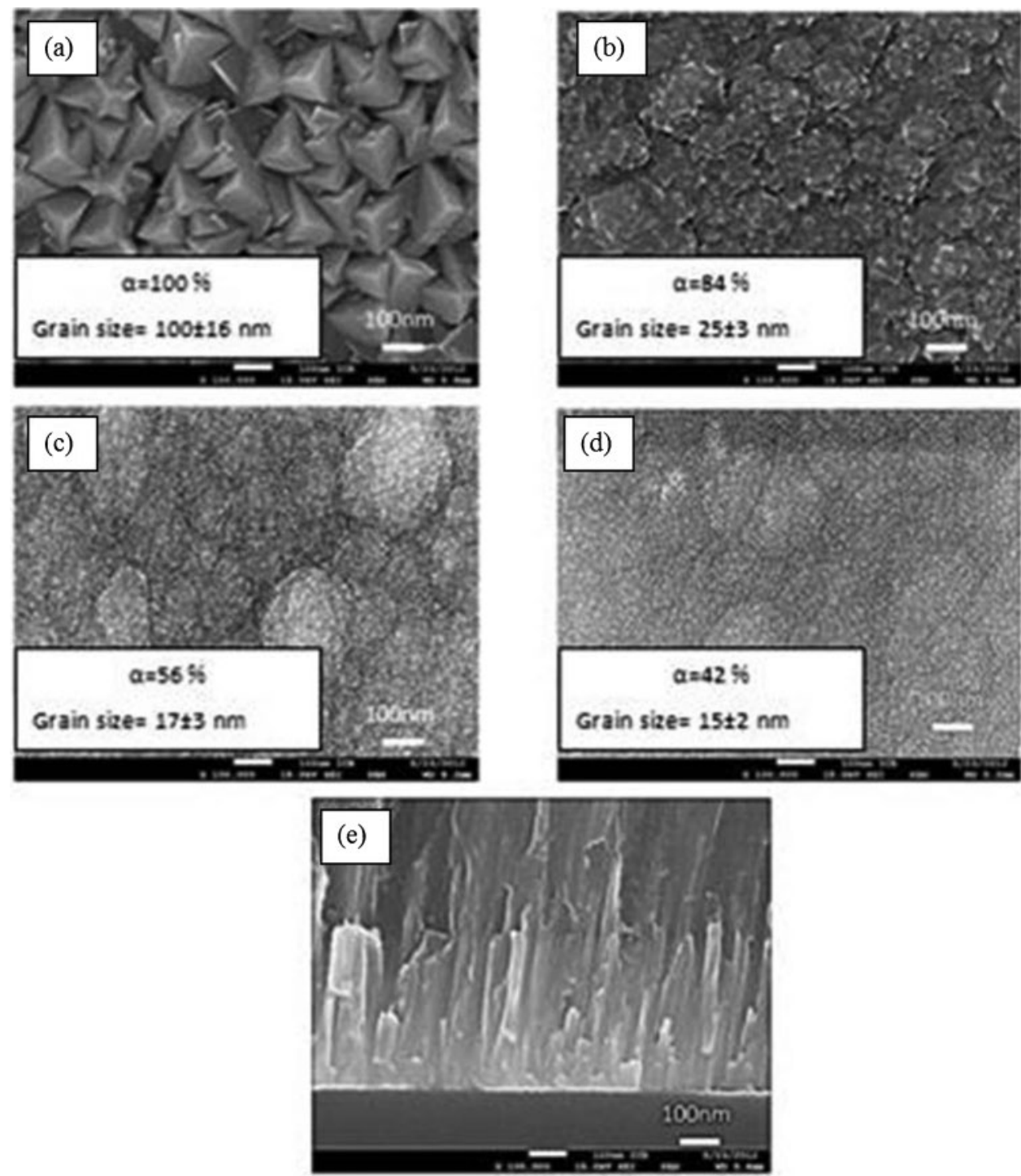

4 High resolution SEM observations of CrSiN films with various duty cycles of a $\alpha=100 \%, b \alpha=84 \%, c \alpha=56 \%$ and $d \alpha=42 \%$ and $e$ cross-section image

It has been shown that the Si content, even low, could influence the $\mathrm{CrN}$ coating growth since it tends to limit it, producing dense epitaxial columns, partially flat, which correspond to the morphology found in zone 2 of Thornton's diagram.

Atomic force microscopy images corresponding to different duty cycles are presented in Fig. 5. As it could be noticed, the morphology of the top columns changes from a conical type morphology to a pyramidal one, as the value of $\alpha$ decreases.

However, the surface roughness in both cases was found to be of a few nanometres. As far as the grain size is concerned, an increase in this parameter from 15 to $100 \mathrm{~nm}$ was observed when the duty cycle increased from 42 to $100 \%$. The largest grain size corresponds to $\alpha=100 \%$, which gives rise to a $\mathrm{CrN}$ layer with a cubic structure. These results corroborate those obtained from the HR-SEM studies and are in agreement with those reported by Shah et $a l^{30}$ who have indicated that, by increasing the addition of silicon, a reduction of the grain size will take place. As it was also reported in the literature, ${ }^{31-37}$ this decrease in the grain size indicates the formation of a SiN phase, which will produce the amorphisation of the coating. The XRD results confirm these findings, since it was demonstrated that a decrease in the $\alpha$ value leads to a decrease in the peaks intensity due to broadening (see Fig. 3), which is strongly dependent on the silicon amount.

The AFM results provide also information on the root mean square $R_{\mathrm{q}}$ roughness variation with the duty cycle. As expected from the above results, the root mean square decreases from 11 to $3.6 \mathrm{~nm}$ when $\alpha$ decreases from 100 to $42 \%$. The decrease in the injection time leads to a decrease in the nitrogen concentration in the sputtering chamber and, therefore, in its concentration in the coatings.

It has to be mentioned that, under these conditions, the cleaning process of the silicon target will take place, which will promote a higher reactivity between the nitrogen and silicon. As a consequence, the mobility of the atoms leads to their reorganisation, which has the consequence to obtain a denser and smoother structure like it was shown by carrying out SEM analysis.

\section{Conclusion}

The reactive sputter deposition of $\mathrm{CrSiN}$ thin films has been carried out by means of RGPP. Various chemical compositions were obtained using a constant mass of 


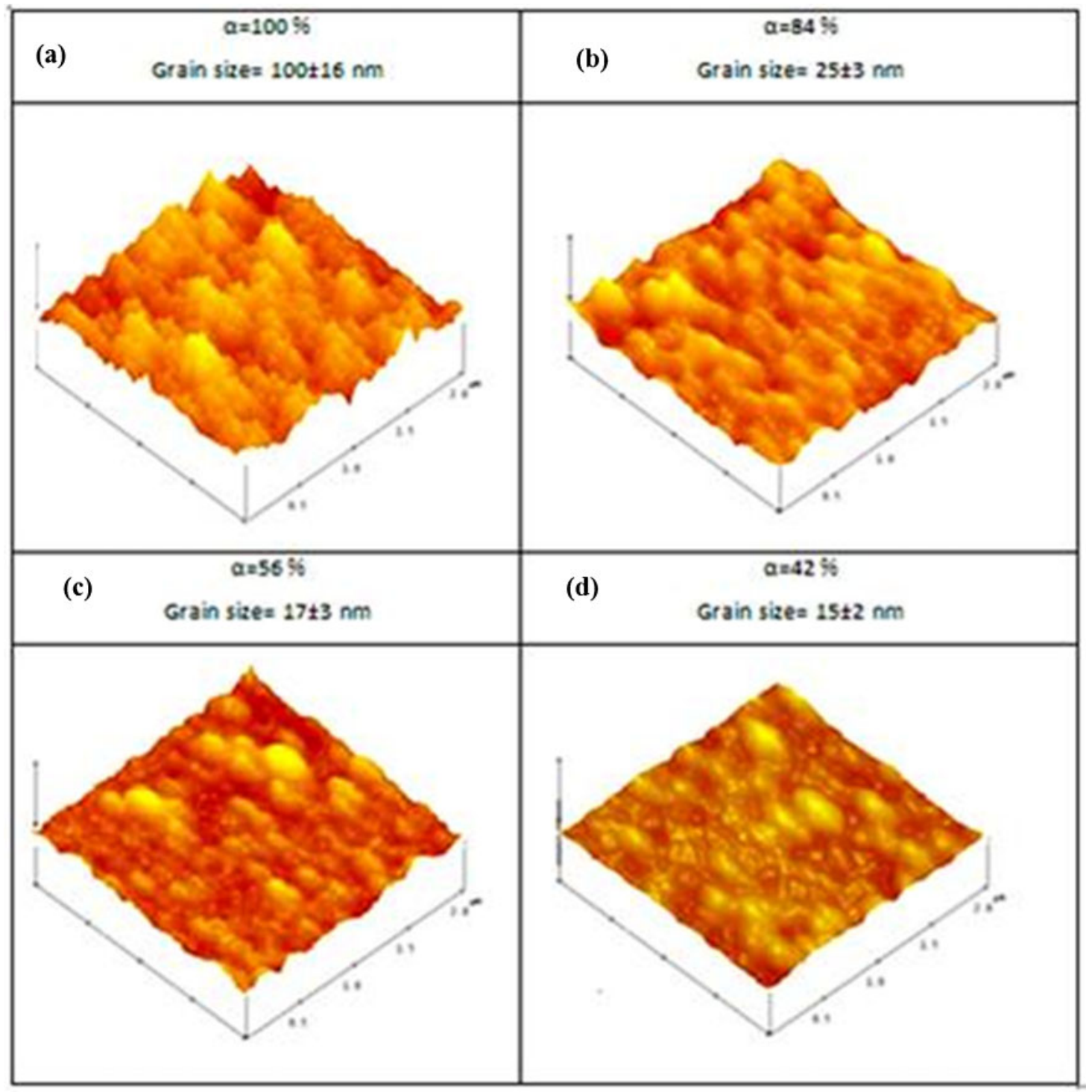

5 Images (AFM) of CrSiN coatings versus duty cycle with a $\alpha=100 \%, b \alpha=84 \%, c \alpha=56$ and $d \alpha=42 \%$

argon, whereas the nitrogen mass flow was controlled according to a rectangular and periodic signal. Various duty cycles used to deposit chromium and silicon nitride and the influence on the chemical composition, structure and morphological behaviour have been studied. Four different coatings were investigated in this work, the duty cycles of which were $42,56,84$ and $100 \%$. The decrease in the injection time of nitrogen leads to the cleaning of the targets used for the deposit. Nitrogen is more reactive with the silicon target than with the chromium one, which has a great impact on the chemical composition of the films. The pulsed injection system gives rise to a more stable deposition, and this is observed in the relative amounts of the chemical quantities that remain unchanged. However, the variation of the duty cycle leads to a change in the amount of silicon and nitrogen in the films, which leads to various combinations with chromium and silicon, and so different compounds were obtained. X-ray diffraction results show the dependence of the $\mathrm{CrSiN}$ structure with the RGPP parameters (duty cycle here), which correlated also with the change of nitrogen and silicon amounts. In fact, a decrease in $\alpha$ leads to an amorphisation of the structure, as well as to rounded and finer grains. The grain size of the films increased from $15 \mathrm{~nm}$ up to $100 \mathrm{~nm}$ with the duty cycle, which explains the preferential orientation (111) accompanied by a reduction in the strain energy in the coatings.

\section{Acknowledgement}

The authors wish to thank Professor L. Imhoff (LICB, University of Burgundy, Dijon, FRANCE) for the HRSEM observations.

\section{References}

1. P. Kuppusami, T. Elangovan, S. Murugesan, R. Thirumurugesan, S. Khan, R. P. George, R. Ramaseshan, R. Divakar, E. Mohandas and D. Mangalaraj: Surf. Eng., 2012, 28, 134-140.

2. J. Ji, Y. Niu, J. Wu and Z. Yu: Surf. Eng., 2014, 30, 36-40.

3. Y. Y. Santana, J. G. La Barbera-Sosa, J. Caro, E. S. Puchi-Cabrera and M. H. Staia: Surf. Eng., 2008, 24, 374-382.

4. P. E. Hovsepian, A. P. Ehiasarian and I. Petrov: Surf. Eng., 2010, 26, 610-614.

5. I. Safi: Surf. Coat. Technol., 2000, 127, 203-218.

6. W. Tillmann, E. Vogli and S. Mohapatra: Surf. Coat. Technol., 2007, 202, 750-754.

7. W. D. Munz and J. Gobel: Surf. Eng., 1987, 3, 47-52.

8. H. N. Shah, R. Jayaganthan and D. Kaur: Surf. Eng., 2010, 26, 629-637. 
9. E. Bousser, M. Benkahoul, L. Martinu and J. E. KlembergSapieha: Surf. Coat. Technol., 2008, 203, 776-780.

10. H. N. Shah, R. Jayaganthan and D. Kaur: Mater. Chem. Phys., 2010, 121, 567-571.

11. P. C. Wo, P. R. Munroe, Z. Li, Z.-T. Jiang, Z. H. Xie, Z. F. Zhoud and K. Y. Li: Mater. Sci. Eng. A, 2012, A534, 297-308.

12. S. Tan, X. Zhang, X. Wu, F. Fang and J. Jiang: Appl. Surf. Sci., 2011, 257, 5595-5600.

13. J.-H. In, S.-H. Seo and H.-Y. Chang: Surf. Coat. Technol., 2008 , 202, 5298-5301.

14. F. Papa, H. Gerdes, R. Bandorf, A. P. Ehiasarian, I. Kolev, G. Braeuer, R. Tietema and T. Krug: Thin Solid Films, 2011, 520, 1559-1563.

15. W. D. Sproul, P. J. Rudnik, C. A. Gogol and R. A. Mueller: Surf. Coat. Technol., 1989, 39-40, 499-506.

16. A. F. Hmiel: J. Vac. Sci. Technol. A, 1985, 3A, 592-595.

17. A. Billard, D. Mercs, F. Perry and C. Frantz: Surf. Coat. Technol., 2001, 140, 225-230.

18. A. J. Aronson, D. Chen and W. H. Class: Thin Solid Films, 1980 72, 535-540.

19. R. P. Howson, N. Danson and I. Safi: Thin Solid Films, 1999, 351, $32-36$

20. N. Martin, J. Lintymer, J. Gavoille and J. Takadoum: J. Mater. Sci., 2002, 37, 4327-4332.

21. R. P. Howson, A. G. Spencer, K. Oka and R. W. Lewin: J. Vac Sci. Technol. A, 1989, 7A, (3), 1230-1234.

22. H. Sekiguchi, A. Kanzawa, T. Imai and T. Honda: J. Vac. Sci Technol. A, 1994, 12A, (6), 3176-3179.

23. S. Berg and T. Nyberg: Thin Solid Films, 2005, 476, 215-230.

24. S. Berg and C. Nender: J. Phys. IV, 1995, 5C, 45-54
25. N. Martin, J. Lintymer, J. Gavoille, J. M. Chappé, F. Sthal, J. Takadoum, F. Vaz and L. Rebouta: Surf. Coat. Technol., 2007, 201, 7720-7726.

26. N. Martin, J. Lintymer, J. Gavoille, J. M. Chappé, F. Sthal, J. Takadoum, F. Vaz and L. Rebouta: Surf. Coat. Technol., 2007, 201, 7733-7738.

27. N. Martin, A. R. Bally, P. Hones, R. Sanjinès and F. Lévy: Thin Solid Films, 2000, 377-378, 550-556.

28. G. Terwagne, J. Colaux, G. A. Collins and F. Bodart: Thin Solid Films, 2000, 377-378, 441-446.

29. Z. Wu, X. Tian, Ch. Gong, Sh. Yang and K. Ch. Paul: Surf. Coat. Technol., 2013, 229, 210-216

30. H. N. Shah, R. Jayaganthan and D. Kaur: Surf. Eng., 2010, 26, 596-601.

31. D. Mercs, N. Bonasso, S. Naamane, J.-M. Bordes and C. Coddet: Surf. Coat. Technol., 2005, 200, 403-407.

32. D. Mercs, P. Briois, V. Demange, S. Lamy and C. Coddet: Surf. Coat. Technol., 2007, 201, 6970-6976.

33. L. Castaldi, D. Kurapov, A. Reiter, V. Shklover, P. Schwaller and J. Patscheider: Surf. Coat. Technol., 2007, 202, 781-785.

34. E. Martinez, S. Sanjinès, A. Karimi, J. Esteve and F. Lévy: Surf. Coat. Technol., 2004, 180-181, 570-574.

35. J. H. Park, W. S. Chung, Y.-R. Cho and K. H. Kim: Surf. Coat. Technol., 2004, 188-189, 425-430.

36. A. Thobor-Keck, F. Lapostolle, A. S. Dehlinger, D. Pilloud, J. F. Pierson and C. Coddet: Surf. Coat. Technol., 2005, 200, 264-268.

37. J. W. Kim, K. H. Kim, D. B. Lee and J. J. Moore: Surf. Coat. Technol., 2006, 200, 6702-6705. 